\title{
Medulla Spinalis Yaralanmalı Hastalarda Osteoporozun Değerlendirilmesi
}

\author{
Assesment of Osteoporosis in Medulla Spinalis Injured Patients \\ Zuhal Bayırlı Karakoyun, Belgin Erhan*, Berrin Gündüz*, Ayşenur Bardak*, Gülsün Iska Elvan** \\ Kastamonu Rehabilitasyon Hastanesi, Kastamonu, Türkiye \\ *istanbul Fizik Tedavi Rehabilitasyon Eğitim ve Araştırma Hastanesi, 1. Ftr Kliniği, İstanbul, Türkiye \\ **Konya Seydişehir Devlet Hastanesi, Seydişehir, Konya, Türkiye
}

\section{Ozet}

Amaç: Osteoporoz medulla spinalis yaralanması (MSY) sonrası görülen komplikasyonlardan biridir ve önemli morbidite nedenlerindendir. Bu çalışmada osteoporozu olan MSYli hastaların demografik özelliklerinin, klinik özelliklerinin ve mevcut risk faktörlerinin osteoporozla ilişkisinin incelenmesi amaçlandı. Gereç ve Yöntemler: Ocak 2009-Haziran 2009 tarihleri arasında hastanemizin MSY takip polikliniklerine başvuran veya rehabilitasyon amacıyla servise yatışı yapılan MSYli hastalardan son 1 yıl içinde çekilmiş mevcut DXA'larında osteoporoz bulunan veya başvuru sonrasında çekilen DXA'larında osteoporoz saptanan 50 yaş altındaki 58 hasta çalışmaya alındı. Bu hastaların yaş, cinsiyet, eğitim durumu, yaralanma süresi ve etiyolojisi, sigara kullanımı, güneş ışığına maruziyeti ve beslenme alışkanlıkları sorgulandı. Nörolojik seviyeleri, komplet mi /inkomplet mi oldukları, ambulasyon durumları ve spastisite varlığı ve şiddeti değerlendirildi. İstatistiksel analizde tanımlayıcı istatistiksel metodlar,Spearman korelasyon testi, Bağımsız Örneklem T Testi, Kruskal Wallis testi, Mann whitney U testi kullanıldı. Anlamlılık p<0,05 düzeyinde değerlendirildi. Bulgular: Hastaların 19'u kadın 39'u erkekti. Yaş ortalamaları 35,71 ะ 8,44 (20-49) yıldı. Hastaların 17'si komplet paraplejik (\%30,7), 4'ü komplet tetraplejik (\%5,1), 25'i inkomplet paraplejik (\%46,1), 12'si inkomplet tetraplejikti (\%17,9). Çalışmamızda osteoporozun en fazla görüldüğü bölge bacaklardı (n: 51). Yaşla KMY değerleri arasında ilişki yoktu. Bacaklarda ve tüm vücutta KMY'nin erkeklerde anlamlı düzeyde daha düşük çıkması dışında (sırasıyla p: 0,002 ve 0,042) cinsiyet açısından fark yoktu. Paraplejiklerde femur boyun ve femur toplam Z skorları tetraplejiklere kıyasla anlamlı olarak daha düşüktü ( $p$ değerleri sırasıyla 0,028 ve 0,021). Tetraplejiklerde kollar T skoru daha düşüktü fakat anlamlı değildi ( $p$ : 0,150). inkomplet hastalarda lomber KMY değerleri kompletlerden anlamlı düzeyde daha düşüktü ( $p: 0,005)$.

Sonuç: MSYli hastalarda erkek cinsiyet, lezyonun inkompletliği ve paraplejik olma kemik yoğunluğunu olumsuz etkilemektedir. Yaş, yaralanma sonrası geçen süre, eğitim durumu, spastisite, ambulasyon düzeyi, sigara kullanımı, güneş ışığı maruziyeti ve diyetle kalsiyum alımının ise kemik yoğunluğu üzerinde anlamlı bir etkisi yoktur. (Türk Osteoporoz Dergisi 2011;17:71-6)

Anahtar kelimeler: Osteoporoz, medulla spialis yaralanması, risk faktörleri

\section{Summary}

Aim: To investigate the relationship between osteoporosis and demographic features, clinical characteristics,risk factors in younger SCI patients. Materials and Methods: Between January-June 2009, all SCI patients admitted to our hospital evaluated and 58 patients who were younger than 50 years who had osteoporosis were enrolled.Patients age, gender, educational status, duration of injury, smoking, sunlight exposure and dietary habits were questioned. Neurological level, completeness, ambulation status and spasticity were assessed. Relationship between these findings with the severity of osteoporosis has been viewed.

Results: There were 19 women. Mean age was 35,7 years. The mean time since injury were 117.7 months. 42 patients were paraplegia (17 complete), 16 were tetraplegia (4 complete). The most common osteoporotic site where the legs. There was no correlation between BMD values with age. In men, the legs and total body BMD were significantly lower.The effect of educational level on BMD was not found. No significant correlation was found between time since injury and BMD. In paraplegics, femoral neck and total femur Z-scores were significantly lower. In tetraplegics, Z scores of the arms were lower, but was not significant. Lumbar BMD values of complete patients were significantly lower than incompletes. Sunlight exposure and consumption of milk/milk products had not a significant positive effect on BMD. 8 patients had therapeutic ambulation, whereas 23 of them had community ambulation. Ambulation status of patients and the presence of spasticity was no effect on BMD. There was no significant correlation between BMD and the severity of spasticity. Smokers ( $n=19)$, bone density was lower in all regions except for femoral neck but were not significantly.

Conclusion: Male gender, paraplegia, and incompleteness negatively effects the bone density. Age, time since injury, education level, spasticity, ambulation level, smoking, sunlight exposure and dietary habits has no significant effect on bone density. (Turkish Journal of Osteoporosis 2011;17:71-6)

Key words: Osteoporosis, medulla spinalis injury, risk factors

Yazışma Adresi/Address for Correspondence: Dr. Zuhal Bayırlı Karakoyun, Kastamonu Rehabilitasyon Hastanesi, Kastamonu, Türkiye

Tel.: +90 36621443 31/524 Gsm: +90 5057511987 E-posta: zuhalbayirli@gmail.com Gelis Tarihi/Received: 21.08.2011 Kabul Tarihi/Accepted: 03.01.2012 Türk Osteoporoz Dergisi, Galenos Yayınevi tarafindan basılmıştır. / Turkish Journal of Osteoporosis, published by Galenos Publishing. 


\section{Giriş}

Medulla spinalis, hareket sisteminin en önemli komponentidir ve yaralanması sonucu birey fiziksel, psikososyal ve ekonomik problemlerle karşı karşıya kalmakta, gelişen komplikasyonlar önemli morbidite ve mortalite sebebi olmaktadır. Osteoporoz da bu komplikasyonlardan biridir.

Osteoporoz, düşük kemik kütlesi ve kemik dokusunun mikromimari yapısının bozulması ile karakterize olan bir hastalıktır (1-2). Tanısı, oluşmuş bir kırığa bağlı olmayıp, laboratuar ve klinik kanıtlara bağlıdır. En sık görülen metabolik kemik hastalığıdır ve primer olmasının yanında medulla spinalis yaralanması sonucu olduğu gibi sekonder osteoporoz olarak da karşımıza çıkmaktadır.

Medulla spinalis yaralanması sonrası osteoporoz gelişimi açısından çeşitli mekanizmalar öne sürülmektedir. Uzun süreli immobilizasyon, diyet alışkanlıklarının değişmesi, güneş ışığına maruziyetin azalması, kalsiyum metabolizmasının bozulması ve nörolojik seviye altında çeşitli nörohormonal faktörler osteoporozun gelişiminden sorumlu tutulmaktadır (3).

Bu çalışmada osteoporoz tanısı almış genç medulla spinalis yaralanmalı hastalarda osteoporoz ile yaş, cinsiyet, nörolojik seviye, yaralanma sonrası geçen süre, ambulasyon durumu ve diyet alışkanlıkları arasındaki ilişkiyi inceledik.

\section{Gereç ve Yöntem}

Bu çalışmaya, Ocak 2009- Haziran 2009 tarihleri arasında medulla spinalis yaralanması nedeniyle rehabilite edilmek üzere hastanemizde yatarak tedavi gören veya polikliniğe başvuran 58 hasta alındı. Çalışma için hastane etik kurulundan onay alındı.

Son 1 yıl içinde çekilmiş mevcut standart ve/veya tüm vücut dual enerji X-ray absorpsiyometrilerinde (DXA) veya başvuru sonrasında çekilen DXA'larında lomber, femur boyun, femur toplam, kollar, bacaklar, veya tüm vücut Z skorlarında osteoporoz saptanan hastalar çalışmaya dahil edildi. Bu bölgelerdeki Z skorları not edildi, lomber bölge değerlerinin ortalaması alındı. 50 yaş ve altındaki hastalar çalışmaya dahil edildi, 50 yaş üzeri olan hastalar, 50 yaşın altında olan ancak menopoza girmiş olan hastalar ve DXA da osteoporoz saptanmayan hastalar çalışma dışı bırakıldı. Hastalar yaş, cinsiyet, eğitim durumu, yaralanma tarihi ve yaralanma etiyolojisi açısından değerlendirildi. Alkol ve sigara kullanıp kullanmadıkları sorgulandı. Güneş ışığına maruziyet durumları ve diyetle yeterli süt ve süt ürünleri alıp almadıkları soruldu. Günde en az 20 dakika süre ile ve en az elleri ve yüzü güneş gören hastalar güneş ışığına maruziyeti yeterli olarak kabul edildi. Günde en az üç porsiyon süt ve süt ürünleri tüketen hastaların beslenmesi yeterli olarak kabul edildi.

Hastaların daha önce bilinen osteoporoz öykülerinin olup olmadığı, osteoporozu olanların tedaviye uyumları ve tedaviye devam etmeyenlerin bırakma nedenleri not edildi.

Hastalar 2002 ASIA nörolojik muayene standartlarına göre muayene edildi, Ashworth skalasına göre spastisite yönünden muayene edildi ve spastisitesi olanların spastik kas grupları not edildi. Hastaların ambulasyon durumları değerlendirilerek tekerlekli sandalye seviyesinde, terapötik ambule ve fonksiyonel ambule şeklinde üç grup belirlendi.

Verilerin analizi SPSS for Windows (Version 16.0)" bilgisayar paket programı ile değerlendirildi. Değerlendirme sırasında tanımlayı ı istatistiksel metodlara (Ortalama, Standart Sapma) ek olarak parametrik hesaplamalarda Spearman korelasyon testi, nonparametrik hesaplamalarda Independent sample T test, Kruskal Wallis test, Mann Whitney U Test kullanıldı. Sonuçlar \%95'lik güven aralığında, anlamlılık p<0,05 düzeyinde değerlendirildi.

\section{Bulgular}

Çalışmada, Ocak 2009- Haziran 2009 tarihleri arasında medulla spinalis yaralanması nedeniyle rehabilite edilmek üzere hastanemizde yatarak tedavi gören veya polikliniğe başvuran 58 hasta değerlendirildi. Hastaların 39'u erkek $(\% 67,2), 19^{\prime} u$ kadın $(\% 32,8)$ idi. Yaş ortalaması 35,71 $\pm 8,44$ (20-49) idi. Eğitim durumları okuma yazma yok $3(\% 5,2)$, okur yazar $5(\% 8,6)$, ilköğretim 24 $(\% 41,4)$, lise mezunu $18(\% 31,0)$, üniversite $8(13,8)$ idi.

Yaralanma sonrası geçen süre ortalama $117,74 \pm 102,13$ aydı (6-394, median 83). Yaralanma etiyolojisine bakıldığında en sık sebep trafik kazalarıydı (n: 19,\%32,8), bunu yüksekten düşme takip ediyordu (n: 15, \%25,9). Yaralanma etiyolojilerine göre dağılım Tablo 1'de verilmiştir.

Hastaların 16 tanesi tetraplejik (\%27,6), 42 tanesi paraplejikti $(\% 72,4)$. Tetraplejiklerin yaş ortalaması $(33,00 \pm 9,79)$, paraplejiklerin yaş ortalaması $(36,74 \pm 7,74)$ idi. İki grup arasındaki yaş farkı anlamlı değildi $(p: 0,133)$. Toplam hasta populasyonunun $21^{\prime} i$ komplet yaralanmalı, 37'si inkomplet yaralanmalıydı. ASIA sınıflandırmasına göre hastaların dağılımı Tablo 2'de verilmiştir.

Bölgesel olarak osteoporoz değerlendirmesi yapıldığında en fazla osteoporoz bacaklarda görülmekteydi (n:51). Bu hastaların 14 tanesi tetraplejik, 37 tanesi paraplejikti. Bölgelere göre osteporoz dağılımı Tablo 3'de verilmektedir.

Hastaların 42'si $(\% 72,4)$ süt ve süt ürünlerini yeterli oranda almaktaydı. 44 hastanın $(\% 75,9)$ güneş ışığına maruziyeti yeterliydi.Tekerlekli sandalye seviyesindeki hastaların sayısı 27 $(\% 46,6)$ di. 8 hasta $(\% 13,8)$ terapötik ambulasyon sağlayabilirken, kalan hastalar $(\% 39,7)$ fonksiyonel ambule olabiliyordu.

Üst ve alt ekstremite kas grupları muayene edilen hastaların 21 tanesinde $(\% 36,2)$ spastisite saptandı. Spastisite en çok 20 hasta ile alt ekstremite fleksör kas grubunda gözlenirken, diğer 1 hastada üst ekstremite fleksör grupta spastisite mevcuttu. Ashworth skalasına göre hastaların \%66,7'sinde Ashworth (Ash) 2 spastisite gözlenmekteydi (n:14,). \%28,6'sında Ash 1 (n:6), $\% 4,8^{\prime}$ inde ise Ash 3 spastisite (n:1) mevcuttu. Hastalardan 19'u $(\% 32,8)$ sigara kullanırken, 2'si $(\% 3,4)$ alkol kullanmaktaydı.

\section{Tablo 1. Yaralanma etiyolojilerine göre dağılım}

\begin{tabular}{|l|c|c|}
\hline Etiyoloji & $\mathbf{n}$ & $\%$ \\
\hline Trafik kazası & 19 & 32,8 \\
\hline Yüksekten düşme & 15 & 25,9 \\
\hline Cerrahi & 5 & 8,6 \\
\hline Üstüne ağırlık düşme & 5 & 8,6 \\
\hline Ateşli silah yaralanması & 5 & 8,6 \\
\hline Transvers myelit & 3 & 5,2 \\
\hline Dalma & 3 & 5,2 \\
\hline Tümör & 2 & 3,4 \\
\hline Enfeksiyon & 1 & 1,7 \\
\hline n:olgu sayııı & & \\
\hline
\end{tabular}


Hastaların 23 tanesinde öncesinde osteoporoz öyküsü mevcuttu $(\% 39,7)$. Osteoporoz öyküsü olan hastaların 10'u tedaviye devam etmiyordu. Bırakma nedeni hastaların tamamında hastanın iyileşme olmaksızın tedaviyi kendi isteğiyle bırakmasıydı.

Cinsiyete göre $z$ skorlarındaki değişim bağımsız gruplarda t testi ile incelendiğinde bacaklar $(p=0,002)$ ve tüm vücut $(p=0,042)$ değerlerinde istatistiksel olarak anlamlı bir farklılık olduğu belirlenmiştir. Erkeklerde bacaklar ve tüm vücut değerlerinin ortalamalarının daha düşük olduğu görülmüştür.

Yaş ile z skorlarının ilişkisi korelasyon analizi ile incelendiğinde istatistiksel olarak anlamlı bir ilişki bulunamadı. Sırasıyla istatistiksel anlamlılık dereceleri yaş ile lomber $(p=0,959)$, yaş ile femur boyun $(p=0,207)$, yaş ile femur toplam $(p=0,635)$, yaş ile kollar $(p=0,538)$, yaş ile bacaklar $(p=0,329)$ ve yaş ile tümvücut $(p=0,851)^{\prime}$ di.

Yaralanma süresi ile z skorlarının ilişkisi korelasyon analizi ile incelendiğinde istatistiksel olarak anlamlı bir ilişki bulunamadı. Sırasıyla istatistiksel anlamlılık dereceleri yaralanma ile lomber $(p=0,412)$, yaralanma ile femur boyun $(p=0,492)$, yaralanma ile femur toplam $(p=0,535)$, yaralanma ile $\operatorname{kollar}(p=0,100)$, yaralanma ile bacaklar $(p=0,151)$ ve yaralanma ile tüm vücut $(p=0,319)^{\prime} d u$.

Eğitim durumuna göre z skorlarındaki değişim kruskal wallis analizi ile incelendiğinde istatistiksel olarak anlamlı bir farklılık bulunamadı. Sırasıyla anlamlılık dereceleri lomber $(p=0,923)$, femur boyun $(p=0,847)$, femur toplam $(p=0,930)$, kollar $(p=0,346)$, bacaklar $(p=0,506)$ ve tüm vücut $(p=0,557)^{\prime}$ ydi.

Pleji durumuna göre z skorlarındaki değişim bağımsız gruplarda $t$ testi ile incelendiğinde femur boyun $(p=0,028)$ ve femur toplam $(p=0,021)$ değerlerinde istatistiksel olarak anlamlı bir farklılık olduğu belirlendi. Paraplejik olanlarda tetraplejik olanlara göre femur boyun ve femur toplam z değerlerinin ortalamalarının daha düşük olduğu bulundu. Tetraplejik ve paraplejiklerdeki kemik mineral yoğunluğu ortalamaları Tablo 4'de verilmiştir.

Komplet/inkomplet oluşuna göre z skorlarındaki değişim bağımsız gruplarda $t$ testi ile incelendiğinde sadece lomber $(p=0,005)$ değerlerinde farklılık olduğu ve inkomplet olanlarda lomber değerlerinin ortalamasının daha düşük olduğu belirlendi. Bulgular Tablo 5'de verilmiştir.

Diyetle yeterli kalsiyum alanlarla almayanlar arasında osteoporoz açısından istatiksel olarak anlamlı fark yoktu. Sırasıyla anlamlılık dereceleri lomber $(p=0,988)$, femur boyun $p=0,612$, femur toplam $p=0,597$, kollar $p=0,958$, bacaklar $p=0,276$ ve tüm vücut $p=0,168^{\prime}$ di. Güneş ışığını yeterli oranda görenler ve görmeyenlerde z skorlarındaki değişim bağımsız gruplarda t testi

\section{Tablo 2. ASIA sınfflandırmasına göre hastaların dağlımı}

\begin{tabular}{|l|c|c|c|}
\hline ASIA sınıflaması & Tüm Vakalar N: $\mathbf{5 8}(\%)$ & Tetraplejikler N: 16 (\%) & Paraplejikler N: $\mathbf{4 2}(\%)$ \\
\hline ASIA A (Komplet) & $21(\% 36,2)$ & $4(\% 25,0)$ & $17(\% 40,5)$ \\
\hline ASIA B (İnomplet) & $15(\% 25,9)$ & $7(\% 43,8)$ & $8(\% 19,0)$ \\
\hline ASIA C (İnkomplet) & $16(\% 27,6)$ & $2(\% 12,5)$ & $3(\% 33,3)$ \\
\hline ASIA D (Inkomplet) & $6(\% 10,3)$ & $3(\% 18,8)$ & \\
\hline
\end{tabular}

Tablo 3. Bölgelere göre osteoporozu olan hastaların dağıımı

\begin{tabular}{|l|c|c|c|}
\hline Bölge (Z Skoru) & Bütün Hastalar N: 58 (\%) & Tetraplejikler N: 16 (\%) & Paraplejikler N: 42 (\%) \\
\hline Lomber & $5(\% 8,6)$ & $0(\% 0)$ & $5(\% 11,9)$ \\
\hline Femur Boyun & $25(\% 43,1)$ & $4(\% 25,0)$ & $34(\% 80,0)$ \\
\hline Femur Toplam & $43(\% 74,1)$ & $9(\% 56,3)$ & $5(\% 11,9)$ \\
\hline Kollar & $7(\% 12,1)$ & $2(\% 12,5)$ & $37(\% 88,1)$ \\
\hline Bacaklar & $51(\% 87,9)$ & $14(\% 87,5)$ & $14(\% 33,3)$ \\
\hline Tüm Vücut Toplam & $18(\% 31,0)$ & $4(\% 25,0)$ & \\
\hline n:vaka sayıs &
\end{tabular}

Tablo 4. Tetraplejik ve paraplejiklerde kemik mineral yoğunluğu ortalamaları

\begin{tabular}{|c|c|c|c|}
\hline Z skoru & Tetraplejik N:16 & Paraplejik N:42 & $p$ \\
\hline Lomber & $0,3 \pm 1,3$ & $0,8 \pm 2,1$ & 0,375 \\
\hline Femur boyun & $-0,8 \pm 2,2$ & $-2,0 \pm 1,7$ & 0,028 \\
\hline Femur toplam & $-1,8 \pm 1,6$ & $-2,8 \pm 0,9$ & 0,021 \\
\hline Kollar & $-0,9 \pm 1,3$ & $-0,3 \pm 1,1$ & 0,150 \\
\hline Bacaklar & $-4,4 \pm 1,0$ & $-4,4 \pm 1,9$ & 0,903 \\
\hline Tüm vücut toplam & $-1,6 \pm 0,7$ & $-1,5 \pm 1,1$ & 0,968 \\
\hline
\end{tabular}


Tablo 5. Komplet ve inkomplet hastaların kemik mineral yoğunluk ortalamaları

\begin{tabular}{|c|c|c|c|}
\hline Z Skoru & Komplet N:21 & İnkomplet N:37 & $p$ \\
\hline Lomber & $1,6 \pm 1,7$ & $0,1 \pm 1,8$ & 0,005 \\
\hline Femur boyun & $-1,4 \pm 1,9$ & $-1,8 \pm 1,9$ & 0,474 \\
\hline Femur toplam & $-2,7 \pm 0,9$ & $-2,4 \pm 1,4$ & 0,418 \\
\hline Kollar & $-0,1 \pm 1,1$ & $-0,7 \pm 1,2$ & 0,086 \\
\hline Bacaklar & $-4,5 \pm 1,9$ & $-4,3 \pm 1,6$ & 0,671 \\
\hline Tüm vücut toplam & $-1,5 \pm 0,9$ & $-1,6 \pm 1,0$ & 0,759 \\
\hline
\end{tabular}

ile incelendiğinde istatistiksel olarak anlamlı bir farklılık olmadığı belirlendi. Sırasıyla anlamlılık dereceleri lomber $p=0,911$, femur boyun $p=0,463$, femur toplam $p=0,555$, kollar $p=0,577$, bacaklar $p=0,310$ ve tüm vücut $p=0,277^{\prime} y d i$.

Ambulasyon durumuna göre z skorlarındaki değişim kruskal wallis analizi ile incelendiğinde istatistiksel olarak anlamlı bir farklılık bulunamadı. Sırasıyla anlamlılık dereceleri lomber $p=0,372$, femur boyun $p=0,853$, femur toplam $p=0,786$, kollar $p=0,175$, bacaklar $p=0,092$ ve tüm vücut $p=0,532$ 'ydi.

Spastisitesi olan ve olmayanlarda z skorlarının değişimi bağımsız gruplarda t testi ile incelendiğinde istatistiksel olarak anlamlı bir farklılık olmadığı belirlendi. Sırasıyla anlamlılık dereceleri lomber $p=0,344$, femur boyun $p=0,952$, femur toplam $p=0,876$, kollar $p=0,571$, bacaklar $p=0,745$ ve tümvücut $p=0,524$ 'dür. Spastisitesi olan hastalarda Ashworth skalasına göre spastisite şiddetiyle kemik yoğunluk ölçümleri karşılaştııldı. Üst ekstremite fleksör grupta spastisitesi olan 1 hasta olduğu için korelasyon değerlendirmesi yapılamadı. Alt ekstremite fleksör grupta spastisitesi olan 20 hastada Ash skoru ile alt ekstremite z skorlarının değişimi Mann Whitney $U$ testi ile incelendiğinde istatistiksel olarak anlamlı bir farklılık bulunamadı. Femur boyun için $p=0,861$, femur toplam için $p=0,692$ ve bacaklar için $p=0,657^{\prime}$ ydi.

Sigara kullanımına göre z skorlarındaki değişim bağımsız gruplarda t testi ile incelendiğinde istatistiksel olarak anlamlı bir farklılık olmadığı belirlendi. Sırasıyla anlamlılık dereceleri lomber $p=0,925$, femur boyun $p=0,719$, femur toplam $p=0,688$, kollar $p=0,132$, bacaklar $p=0,359$ ve tüm vücut $p=0,629^{\prime} d u$. Alkol kullanımına göre z skorlarındaki değişim alkol kullanan 2 kişi ve kullanmayan 56 kişi olduğundan istatistiksel olarak karşılaştırılamamıştır.

Çalışma öncesinde osteoporoz öyküsü bulunan hastalardan halen tedaviye devam edenlerle ihmal nedeniyle tedaviyi bırakmış olanların z skorlarının değişimi bağımsız gruplarda t testi ile incelendiğinde istatistiksel olarak anlamlı bulunmadı. Değerler sırasıyla; lomber $p=0,089$, femur boyun $p=0,301$, femur toplam $p=0,841$, kollar $p=0,931$, bacaklar $p=0,899$ ve tüm vücut $p=0,370$ idi

$\mathrm{Bu}$ çalışmadaki medulla spinalis yaralanmalı hastalarda en fazla osteoporoz bacaklarda görülmekteydi. Kadın ve erkekler arasında KMY (kemik mineral yoğunluğu) açısından değerlendirme yapıldığında bacaklar ve tüm vücut Z skoru ortalamaları erkeklerde anlamlı olarak daha düşüktü. Hastaların yaşları ile kemik yoğunlukları arasında ilişki bulunamadı.Yaralanma sonrası geçen süre ile hastaların Z skorları arasında ilişki yoktu. Eğitim düzeyinin kemik mineral yoğunlukları üzerine anlamlı bir etkisi bulunamadı. Paraplejiklerde alt ekstremite KMY değerleri tetraplejiklere göre anlamlı olarak daha düşük bulundu. Tetraplejiklerde ise kollar daha düşüktü fakat anlamlı değildi.Inkomplet hastalarda lomber KMY değerleri kompletlerden anlamlı olarak daha düşüktü.
Hastaların ambulasyon durumlarının Z skorları ile ilişkisi incelendiğinde anlamlı bir bulgu yoktu. Spastisite varlığının ve spastisitesi olan hastalarda spastisite şiddetinin kemik yoğunlukları üzerine anlamlı bir etkisi yoktu. Daha öncesinde osteoporoz tanısı almış olan hastalardan osteoporoz tedavisine devam edenlerle ihmal nedeniyle tedaviyi bırakmış olanların Z skorları arasında anlamlı bir fark yoktu.

Diyetle yeterli kalsiyum alımının ve yeterli düzeyde güneş ışığı maruziyetinin kemik yoğunlukları üzerine anlamlı bir etkisi bulunamadı.Sigara kullanan hastalarda femur boyun hariç tüm değerler daha düşük olmakla birlikte sigara kullanımının kemik yoğunluğu üzerine anlamlı düzeyde bir etkisi bulunamadı.

\section{Tartışma}

Medulla spinalis yaralanması sonrası görülebilen komplikasyonlardan biri olan osteoporoz önemli morbidite nedenlerinden biridir. Değişen oranlarda görülebilmekle birlikte lezyonun seviyesine, komplet ve inkomplet oluşuna, yaralanma sonrası geçen süreye, hastanın yaşına, cinsiyetine, beslenme alışkanlıklarına, güneş ışığı maruziyetine, ambulasyon durumuna, spastisite varlığına, sigara ve alkol kullanımına bağlı olarak şiddeti değişkenlik gösteriyor olabilir. Çalışmamızda bu gibi faktörlerle osteoporozun ilişkisi incelenmiştir. ABD'de etiyolojide trafik kazaları \%36,6 ile en sık sebep iken bunu şiddet olayları $(\% 27,9)$, düşmeler $(\% 21,4)$ ve spor yaralanmaları $(\% 6,5)$ izlemektedir. Ülkemizde Karacan ve arkadaşlarının yaptığı çalışmada da trafik kazaları \%48,8 ile en sık neden olarak bulunmuştur (4). Bizim çalışmamızda da etiyolojik faktör olarak trafik kazaları \%32,8 oranla ilk sıradaydı ve bunu \%25,9 ile yüksekten düşme izliyordu.

Hastalarımızda en fazla osteoporoz görülen bölge bacaklardı ve bu veri yaralanma seviyesinin altında osteoporoz görülme olasılığının fazla olduğu fikrini desteklemekteydi. Bir çalışmada fiziksel olarak aktif medulla spinalis yaralanmalı hastalar sağıkılı bireylerle karşılaştırılmış, medulla spinalis yaralanmalı hastaların alt ekstremite kemik yoğunluğu değerleri sağlıklı bireylere kıyasla anlamlı olarak daha düşük bulunmuş, kollarda ve omurgada ise fark bulunamamıştır (5).

Lezyonun komplet oluşu, parapleji, artmış yaş ve yaralanma süresi, kadın cinsiyet medulla spinalis yaralanması hastalarında osteoporoz risk faktörleri arasında kabul edilmektedir (6). Çalışmamızda kadın ve erkekler osteoporoz şiddeti açı sından karşılaştııılmış ancak kabul gören risk faktörlerinin aksine bacaklar ve tüm vücut kemik yoğunluğu erkeklerde daha düşük çıkmış ve anlamlı bulunmuştur. Yaşla birlikte osteoporoz şiddeti artması beklenen hastaların kemik mineral yoğunlukları incelendiğinde böyle bir anlamlı ilişki görülmemektedir. Medulla spinalis yaralanmasının nörohormonal 
faktörlere bağlı olarak kemik yoğunluğu üzerindeki olumsuz etkisi hastaların yaşa bağlı kemik kaybındaki artışı maskelemiş olabilir. Nitekim MSY olmayan populasyonda yaş arttıkça kemik yoğunluğunun azaldığı bilinmektedir. Yaralanma sonrası geçen sure ile kemik mineral yoğunluğunun ilişkisinin anlamlı düzeyde çıkmaması da hasta grubumuzun yaralanma süresinin nispeten uzun olmasına bağlanabilir. MSY sonrası en hızlı kemik kaybının ilk 6 ayda olduğu bilinmektedir. Garland ve arkadaşlarının yaptığı çalışmada hastaların lomber kemik yoğunlukları yaşla pozitif korele, bacak kemik yoğunlukları ise negatif korele bulunmuştur (7). Lomber değerlerde saptanan bu bulgu sağlıklı populasyonda beklenenin aksine medulla spinalis yaralanmalı hastalarda aksiyel yüklenmeye bağlı olarak lomber kemik yoğunluklarının artıyor olabileceğini düşündürmektedir. Çalışmamızdaki hastaların lomber kemik yoğunlukları ile yaşları arasında bu çalışmadan farklı olarak korelasyon saptanmamıştır.

Parapleji ve tetrapleji açısından bakıldığında 1992 de Garland ve arkadaşlarının yaptığı çalışmada 45 medulla spinalis yaralanmalı hasta değerlendirilmiş ve kollar ve gövde kemik mineral yoğunluğu değerleri paraplejik ve tetraplejiklerde anlamlı olarak farklı iken, pelvis ve altında iki grup arasında fark bulunamamıştır (3). 2007 yılında yayınlanmış bir çalışmada 15 komplet paraplejik hasta incelenmiş ve kemik mineral yoğunlukları femur boyun ve trokanterde azalmış iken lomberde değişiklik saptanmamıştır (8). Bizim çalışmamızda paraplejik ve tetraplejikler karşılaştırıldığında iki grup alt ekstremite değerleri farklı bulunmuştur. Paraplejiklerin femur boyun ve femur toplam yoğunlukları tetraplejiklerden anlamlı olarak daha düşük çıkmıştır. Kollarda ise diğer çalışmalarla paralel olarak tetraplejiklerde daha düşük kemik yoğunluğu saptanmış olmakla beraber bu düşüklük anlamlı bulunamamıştır. Grup içi incelemelerde hem paraplejik hem de tetraplejiklerde alt ekstremite değerleri kollar ve lombere kıyasla daha düşük bulunmuştur. Her iki grupta da lomber kemik yoğunluklarının korunduğu görülmektedir. Medulla spinalis yaralanması sonrası omurga kemik yoğunluklarının korunduğu ve hatta arttığı yönünde çalışmalar yayınlanmıştır. Broholm ve arkadaşları 2005 yılında 18 medulla spinalis yaralanmalı erken menopozal kadın hastanın kemik mineral yoğunluklarını incelemiş ve lomber bölge hariç tüm değerlerde düşme saptamışlardır (9). Garland ve arkadaşları da 2001 yılında 31 kronik komplet yaralanmalı kadın hastayı incelemiş ve yaralanma sonrası geçen süreye paralel olarak lomber kemik yoğunluğunun korunduğunu ya da arttığını saptamışlardır (7). Lomber bölgenin kemik kaybından korunması oturmaya bağı gravitasyonel yüklenmeye bağlanmaktadır. Szollar ve arkadaşları da yaptıkları çalışmada hastaların tümünde yaralanmadan sonra vertebral kemik mineral yoğunluklarının arttığını bulmuşlardır (10)

Çalışmamızda inkomplet hastaların lomber değerleri kompletlere göre daha düşük bulunmuştur ve istatistiksel olarak anlamlıdır. Vlychou ve arkadaşları yaptığı çalışmada komplet ve inkomplet yaralanmalı hastaları karşılaştırmışlar ancak iki grup arasında kemik mineral yoğunluklarında fark gösterememişlerdir (11). 46 erkek medulla spinalis yaralanmalı hastanın incelendiği kesitsel bir çalışmada bizim çalışmamızın tersine komplet hastaların lomber kemik yoğunlukları inkompletlerden anlamlı olarak daha düşük bulunmuştur. Aynı çalışmada komplet lezyonlu hastaların proksimal femur KMY değerleri inkomplet hastalardan daha düşük olmasına rağmen, bu fark anlamlı bulunmamıştır (12). Bir başka çalışmada yine komplet ve inkompletler arasında fark bulunamamıştır (13).
İmmobilizasyonun önceleri osteoporoz mekanizmasındaki esas neden olduğu düşünülmüştür. Fakat daha sonra bazı nörohormonal faktörlerin osteoporozda etkili olduğu ileri sürülmüştür. Çalışmamızda hastaların ambulasyon durumları ile kemik mineral yoğunlukları karşılaştırılmış tekerlekli sandalye seviyesindeki hastalar, ayakta denge düzeyindeki hastalar ve ambule olabilen hastalar arasında kemik yoğunlukları açısından anlamlı bir fark bulunamamıştır. Bu da osteoporoz mekanizmasındaki güncel fikirleri desteklemektedir. Giangregorio ve ekibinin yaptığı bir çalışmada medulla spinalis yaralanması olan ve yaralanma süresi 2-6 ay arasında değişen 5 hastaya lokomat yardımıyla 24 hafta süre ile yürüme egzersizleri yaptırılmış ve kemik yoğunluklarında başlangıç değerlerine göre anlamlı bir değişme saptanamamıştır (14). Bulgularımızın aksine 2008 yılında yapılan bir çalışmada ayakta dengesi olan 27 hasta ayakta duramayan 27 hasta ile karşılaştırılmış ve ayakta dengesi olan medulla spinalis yaralanmalı hastalarda alt ekstremite kemik mineral yoğunlukları anlamlı olarak daha yüksek bulunmuştur (15). Çalışmamıza paralel olarak bazı çalışmalarda ambulasyon seviyesi ayakta durma, yürüme gibi aktivitelerin yek başına kemik mineral yoğunluğunu arttırmadığı, osteoporozu önlemediği sonucuna varılmıştır (13,16-17). Yine bir çalışmada 20 hasta 12 hafta boyunca otuzar dakikalık periyotlar halinde ayakta durma masası yardımıyla dik pozisyonda tutulmuş ve alt ekstremite kemik yoğunluklarında anlamlı bir artış sağlanamamıştır (18).

Çalışmamızda günde en az 3 porsiyon süt ve süt ürünleri tüketen hastalar diyetle yeterli kalsiyum alıyor kabul edilmiş, günde en az 20 dakika dışarı çıkan hastalar yeterli güneş ışığı maruziyeti var olarak kabul edilmiş ve beslenmesi ve güneş ışığı yetersiz olan hastalarla kemik yoğunlukları karşılaştırılmıştır. Diyetle kalsiyum almanın ve yeterli düzeyde güneş ışığı maruziyetinin kemik yoğunluğu üzerine olumlu etkisi saptanmamıştır.Bu bulgularımız diyetle kalsiyum alımının ve güneş ışığı maruziyetinin kemik üzerine olumlu etkileri olduğu bilgisini desteklememektedir. Murphy ve arkadaşlarının 1994 de yaptıkları bir çalışmada yaşları 44-74 arasında değişen 284 kadın içtikleri süt miktarına göre gruplara ayrılmış, DEXA'ları çekilmiş ve kemik mineral yoğunluklarının süt miktarı ile doğru orantılı olarak arttığı bulunmuştur (19).

Elli dört motor komplet medulla spinalis yaralanmalı hastanın incelendiği bir çalışmada hastalar Ashworth skalası ile spastisite yönünden değerlendirilmiş ve periferik kantitatif bilgisayarlı tomografi ile değerlendirilen femur, tibia ve radius kemik yoğunlukları spastisite ile doğru orantılı olarak artmış bulunmuştur (20). Löfvenmark ve arkadaşlarının 9 tanesinde spastisite olan toplam 18 motor komplet medulla spinalis yaralanmalı hasta üzerinde yaptıkları incelemede spastisitenin kemik mineral yoğunluğu üzerinde etkisi olmadığı bulunmuştur (21). Bizim çalışmamızda da spastisite varlığının kemik mineral yoğunluğu üzerine etkisi bulunamamış, ve alt ekstremitede spastisitesi olan hastalarda spastisite şiddetli ile alt ekstremite KMY arasında anlamlı düzeyde bir korelasyon saptanmamıştır.

Sigara kullanımı osteporoz için risk faktörü olarak kabul edilmektedir. Bauman ve arkadaşlarının 2005 de yaptıkları bir çalışmada 8 tanesi sigara kullanan toplam 19 medulla spinalis yaralanmalı hastaya D vitamini verilmiş ve 24 aylık takip sonucunda sigara kullanmayan 11 hastanın bacak kemik mineral yoğunlukları anlamlı olarak yükselmişken, kullananlarda anlamlı değişiklik saptanmamıştır (22). Çalışmamızda sigara içen hastalarda femur boyun haricindeki tüm bölgelerde Z skorları ortalamaları içmeyenlere kıyasla daha düşüktü fakat anlamlı değildi. 
Alkol kullanımı da osteoporoz risk faktörleri arasındadır. Çalışmamızda alkol kullanım öyküsü olan 2 hasta mevcuttu ve kollar ve lomber dışındaki tüm Z skorlarında genel hasta populasyonun ortalamasına kıyasla düşüklük mevcuttu. Spencer ve arkadaşları alkol rehabilitasyon merkezine başvuran 96 erkek hastanın röntgenogramlarını incelediğinde \%47'sinde kemik kaybı olduğunu saptamışlardır (23). Röntgenogramlarda kemik kaybının saptanabilmesi için \%30 kayıp olmsı gerektiği de göz önünde bulundurulmalıdır. Yine bir başka çalışmada 84,484 kadın anket yoluyla değerlendirilmiş ve alkol alımının kalça ve önkol kırıklarını doza bağımlı oranda arttırdığı saptanmıştır (24). Çalışmamızdaki bulgular literatür ile uyumlu olmakla beraber vaka sayısı anlamlı bir değerlendirme yapmak için yeterli değildir.

\section{Kaynaklar}

1. Francis J, Bonner Jr, Charles H, Chesnut III, Lindsay R, Osteoporoz. Editör DeLisa JA. Fiziksel Tıp ve Rehabilitasyon Ilkeler ve Uygulamalar. Güneş Tıp Kitapevleri; 2007. p. 699-719.

2. Erhan GB, Yılmaz H. Medulla Spinalis lezyonunda Osteoporozun Tanı ve Tedavisi. Türkiye Fiziksel Tıp ve Rehabilitasyon Dergisi 2001;47.

3. Garland DE, Steward CA, Adkins RH, Hu SS, Rosen C, Liotta FJ, et al. Osteoporosis after spinal cord injury. J Orthop Res 1992;10:371-8.

4. Karacan I, Koyuncu H, Pekel O, Sümbüloglu G, Kirnap M, Dursun $\mathrm{H}$, et al. Traumatic spinal cord injuries in Turkey: a nation-wide epidemiological study. Spinal Cord 2000;38:697-701.

5. Jones $L M$, Legge $M$, Goulding $A$. Intensive exercise may preserve bone mass of the upper limbs in spinal cord injured males but does not retard demineralisation of the lower body. Spinal Cord 2002; 40:230-5.

6. Douglas E. Garland MD, Rodney H. Adkins PhD, Charles A, Stewart MD. Fracture Threshold and Risk for Osteoporosis and Pathologic Fractures in Individuals with Spinal Cord Injury. Topics in Spinal Cord Injury Rehabilitation 2005:11:61-9.

7. Garland DE, Adkins RH, Stewart CA, Ashford R, Vigil D. Regional osteoporosis in women who have a complete spinal cord injury. J Bone Joint Surg Am 2001;83:1195-200.

8. Can A, Döşoğlu MS, Karacan i, Karamehmetoğlu S.. Travmatik omurilik yaralanması olan olgularda aksiyel yüklenmenin kemik mineral yoğunluğu üzerine etkisi. Ulus Travma Acil Cerrahi Derg 2007:13:101-5.

9. Broholm B, Pødenphant J, Biering-Sørensen F. The course of bone mineral density and biochemical markers of bone turnover in early postmenopausal spinal cord lesioned females. Spinal Cord 2005:43:674-7.

10. Szollar SM, Martin EM, Sartoris DJ, Parthemore JG, Deftos LJ. Bone mineral density and indexes of bone metabolism in spinal cord injury. Am J Phys Med Rehabil 1998;77:28-35.
11. Vlychou M, Papadaki PJ, Zavras GM, Vasiou K, Kelekis N, Malizos $\mathrm{KN}$, et al. Paraplegia-related alterations of bone density in forearm and hip in Greek patients after spinal cord injury. Disabil Rehabil 2003:25:324-30

12. Sabo D, Blaich S, Wenz W, Hohmann M, Loew M, Gerner HJ. Osteoporosis in patients with paralysis after spinal cord injury. A cross sectional study in 46 male patients with dual-energy X-ray absorptiometry. Arch Orthop Trauma Surg 2001;121:75-8.

13. Dauty $M$, Perrouin Verbe $B$, Maugars $Y$, Dubois C, Mathe JF. Supralesional and sublesional bone mineral density in spinal cord injured patients. Bone 2000;27:305-9.

14. Giangregorio LM, Hicks AL, Webber CE, Phillips SM, Craven BC, Bugaresti JM, et al. Body weight supported treadmill training in acute spinal cord injury: impact on muscle and bone. Spinal Cord 2005;43:649-57.

15. Alekna $V$, Tamulaitiene $M$, Sinevicius $T$, Juocevicius A. Effect of weight-bearing activities on bone mineral density in spinal cord injured patients during the period of the first two years. Spinal Cord 2008;46:727-32.

16. Kunkel CF, Scremin AM, Eisenberg B, Garcia JF, Roberts S, Martinez S. Effect of "standing" on spasticity, contracture, and osteoporosis in paralyzed males. Arch Phys Med Rehabil 1993;74:73-8.

17. Biering-Sørensen $\mathrm{F}$, Bohr $\mathrm{H}$, Schaadt $\mathrm{O}$. Bone mineral content of the lumbar spine and lower extremities years after spinal cord lesion. Paraplegia 1988:26:293-301

18. Ben M, Harvey L, Denis S, Glinsky J, Goehl G, Chee S, et al. Does 12 weeks of regular standing prevent loss of ankle mobility and bone mineral density in people with recent spinal cord injuries? Aust J Physiother. 2005;51:251-6.

19. Murphy S, Khaw KT, May H, Compston JE. Milk consumption and bone mineral density in middle aged and elderly women. BMJ 1994;308:939-41.

20. Eser P, Frotzler A, Zehnder Y, Schiessl H, Denoth J. Assessment of anthropometric, systemic, and lifestyle factors influencing bone status in the legs of spinal cord injured individuals. Osteoporos Int 2005;16:26-34

21. Löfvenmark I, Werhagen L, Norrbrink C. Spasticity and bone density after a spinal cord injury. J Rehabil Med 200941:1080-4.

22. Bauman WA, Spungen AM, Morrison N, Zhang RL, Schwartz E. Effect of a vitamin $D$ analog on leg bone mineral density in patients with chronic spinal cord injury. I Rehabil Res Dev 2005;42:625-34

23. Spencer $H$, Rubio $N$, Rubio $E$, Indreika M, Seitam A. Chronic alcoholism: A frequently overlooked cause of osteoporosis in men. Am J Med 1986:80:393-7.

24. Hernandez-Avila M, Colditz GA, Stampfer MJ, Rosner B, Speizer FE, Willett WC. Caffeine, moderate alcohol intake, and risk of fractures of the hip and forearm in middle-aged women. Am J Clin Nutr 1991;54:157-63. 